Abstract S93 Table 1 Studies assessing treatment response or survival using serial serum mesothelins during treatment

\begin{tabular}{|c|c|c|c|}
\hline $\begin{array}{l}\text { Author } \\
\text { (year) }\end{array}$ & $\begin{array}{l}\text { Treatment } \\
\text { (no. of patients) }\end{array}$ & Outcome measure & Results \\
\hline \multirow[t]{2}{*}{ Hooper (2015) } & P/C- 58 & Mod RECIST CT & $\begin{array}{l}\text { Falling serum mesothelin following chemotherapy associated with longer time } \\
\text { to progression }(\mathrm{p}<0.001) \text { and } \mathrm{OS}(\mathrm{p}=0.031) \text {. }\end{array}$ \\
\hline & BSC- 15 & OS & \\
\hline $\begin{array}{l}\text { Hassan } \\
\text { (2014) }\end{array}$ & $\begin{array}{l}\mathrm{P} / \mathrm{C} \& \text { immuno- } \\
\text { toxin- } 20\end{array}$ & Mod RECIST CT & $\begin{array}{l}\text { Fall in serum mesothelin correlated with radiological response with } 70 \% \\
\text { accuracy }(p=0.003) \text {. }\end{array}$ \\
\hline Franko & G/C- 56, P/C- 9 & Mod RECIST CT & $\begin{array}{l}\text { Significantly lower mean serum mesothelin in partial response or stable } \\
\text { disease compared to progressive disease }(\mathrm{p}=0.001) \text {. }\end{array}$ \\
\hline (2012) & EPP- 1, BSC- 4 & & \\
\hline \multirow[t]{2}{*}{$\begin{array}{l}\text { Hollevoet } \\
(2011)\end{array}$} & P/C- 57 & Mod RECIST CT & $\begin{array}{l}\text { Partial response to chemotherapy correlated with a } 34 \% \text { fall in mesothelin } \\
(p=0.010) \text { compared to a } 54 \% \text { rise in progressive disease }(p<0.001) .\end{array}$ \\
\hline & EPP-5 & & \\
\hline \multirow[t]{2}{*}{$\begin{array}{l}\text { Creaney, } \\
\text { (2011) }\end{array}$} & $\begin{array}{l}\text { Chemo- } 61 \text {, Tri- } 8 \text {, } \\
\text { BSC- } 25\end{array}$ & Mod RECIST CT & $\begin{array}{l}\text { Falling mesothelin was associated with better OS ( } 19 \text { months) compared to } \\
\text { static ( } 13 \text { months) or rising levels ( } 15 \text { months). }(\mathrm{p}=0.001) .\end{array}$ \\
\hline & & OS & \\
\hline $\begin{array}{l}\text { Wheatley-Price } \\
(2010)\end{array}$ & $\begin{array}{l}\text { Chemo- 21, EPP-8, } \\
\text { BSC- } 13\end{array}$ & Mod RECIST CT & $\begin{array}{l}\text { Relative change in serum mesothelin from baseline }(>10 \%) \text { significantly asso- } \\
\text { ciated with disease progression }(p<0.001) \text {. }\end{array}$ \\
\hline
\end{tabular}

P- pemetrexed C- cisplatin G- gemcitabine, Chemo- chemotherapy (not specified), BSC- best supportive care, EPP- extra-pleural pneumonectomy, Tri- trimodality. Mod RECIST CT- Modified Response Evaluation Criteria In Solid Tumors CT, OS- Overall survival.

Introduction and objectives Malignant pleural effusion (MPE) is a rapidly rising healthcare burden and critically hampers the patients' survival and quality of life. Current treatments aim to symptoms' palliation and talc pleurodesis remains a standard therapeutic modality. There is relatively little high quality research data in prediction of patients' survival and successful pleurodesis. Therefore prognostic and therapeutic biomarkers are desperately needed.

Aim To identify and validate novel prognostic and therapeutic biomarkers in MPE.

Methods Clinical data and pleural fluids from MPE patients, prior to treatment have been prospectively collected for TIME2 trial. According to the trial database patients have been classified in two different groups: survival cohort (poor, $n=20 /$ good, $\mathrm{n}=14$ ) and treatment outcome cohort (success, $\mathrm{n}=15 /$ failure, $\mathrm{n}=11$ ). Pleural fluids on enrolment were assessed with mass spectrometry profiling after depletion of the 12 most abundant proteins. Full protein profile analysed with R software and ELISA technique was performed for the validation of the results. Pathway analysis on samples performed with Ingenuity Pathway Analysis software.

Results With the use of mass spectrometry we identified 1,154 proteins in the pleural fluid, 167 of which were statistical significant (two tailed T-Test, $\mathrm{p}<0.05$ ) between survival groups and 97 of which were statistically significant (two tailed T-Test, $\mathrm{p}<0.05$ ) between the pleurodesis groups. Analysis of the data (cross validated by 3 independent core bioinformatic groups) identified 10 survival and 3 pleurodesis biomarkers that were differentially expressed in the favourable prognosis and treatment success group respectively. Exploration of the mass spectrometry data identified pathways that were upregulated on patients with favourable survival that could be used for targeted therapies.

Conclusions Based on unique database survival and therapeutic biomarkers were identified that can potentially stratify patients' management. The results are currently validated on a different retrospective dataset (TIME1 trial) and with a prospective clinical trial (SIMPLE study).

\section{S95 AMBULATORY MANAGEMENT OF PNEUMOTHORAX: IS THERE A NEED FOR A DEDICATED PLEURAL TEAM-LED SERVICE?}

A Fawzi, N Maddekar, S Khan, S Bikmalla, W Osman, U Maqsood, M Haris. Royal Stoke University Hospital, Stoke-on-Trent, UK

\subsection{6/thoraxjnl-2016-209333.101}

Introduction Small, asymptomatic pneumothoraces may be managed as outpatients. Several studies show that small-bore catheters and Heimlich valves may be used in the treatment of pneumothoraces. A systematic review of the literature ${ }^{1}$ showed successful outpatient management of pneumothorax. Despite good evidence to support ambulatory approach, there has been slow development of this service across the UK. We wished to assess the number of potential primary spontaneous pneumothorax patients that could be managed as outpatients in a large teaching hospital.

Methods Hospital attendances of pneumothorax at a large teaching hospital between 2012-2015 were reviewed. Type of 
pneumothorax was characterised: primary spontaneous (PSP), secondary spontaneous (SSP), iatrogenic (IP) and traumatic/postoperative. The data for PSP was then correlated against the data retrieved from the systematic review of outpatient pneumothorax management. ${ }^{1}$

Results Total number of pneumothorax episodes were 877; PSP 266, SSP 229, IP 41 and traumatic/post-operative 341. Average length of stay (LOS) for all episodes of pneumothorax was 12.39 days. LOS for PSP was 6.9 days. Total number of hospital admissions for PSP $(266 / 3=) 88.7$ patients/year. Extrapolated from systematic review ${ }^{1}$ : Successful outpatient PSP management $(88.7 * 78 \%=) 77.1$ patients/year. Potential bed days saved for PSP: $(77.1 * 6.9=) 532$ beds/year.

Conclusions Studies show both spontaneous and iatrogenic pneumothorax may be managed safely as outpatients. Dedicated pleural services will result in correct stratification of patients requiring appropriate interventions. Ambulatory chest drains could be used and inserted by professionals trained in their use.

Advantages to patients: reduced need for hospital admission, greater patient autonomy, improved patient experience, no need to carry chest drain bottle, reduced likelihood of accidental dislodgement of chest drain, reduced time to discharge.

Advantages to trust: admission avoidance, early discharge, reduced costs, reduced complications from chest drain insertions, reduced hospital associated complications, optimised patient care with increased patient satisfaction.

Although we would not advocate the use of ambulatory pneumothorax devices in trauma patients, there is scope to establish whether they can be used post procedural (e.g. pneumothorax following pacemaker insertion).

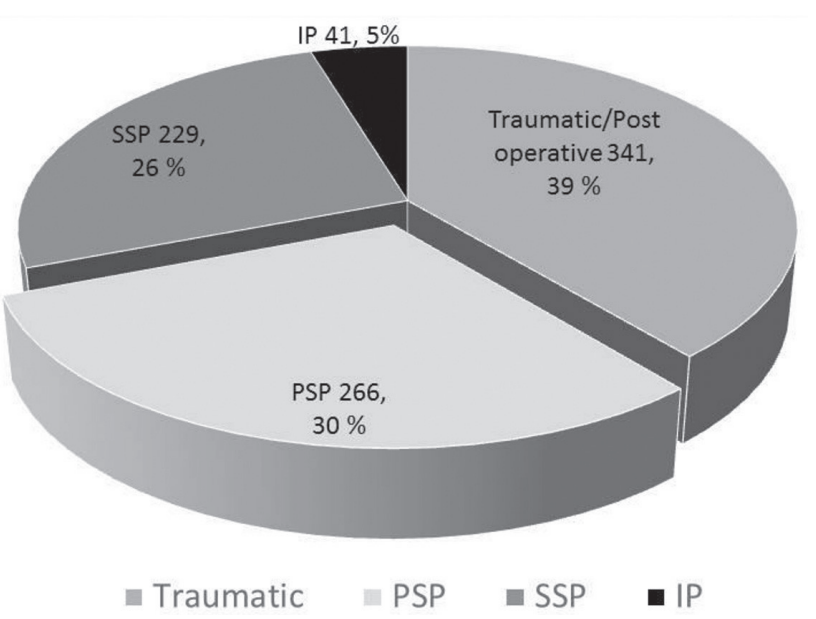

Abstract S95 Figure 1

\section{REFERENCE}

1 Brims FJ, Maskell NA. Ambulatory treatment in the management of pneumothorax: a systematic review of the literature. Thorax 2013;68(7):664-9.

\section{S96 COMPARATIVE OUTCOMES OF OUTPATIENT MANAGEMENT OF PRIMARY AND SECONDARY SPONTANEOUS PNEUMOTHORAX}

FA Khan, RV Reddy, M Naeem, Y Vali, I Masih, N Siddique. Kettering General Hospital, Northamptonshire, UK
Introduction To compare the effectiveness of ambulatory management of primary (PSP) and selected secondary spontaneous pneumothoraces (SSP)

Methods Large PSP and selected SSP patients (WHO performance score $0-1$ ) aged between 16-80 presenting between May 2013 and January 2016, were deemed eligible for the ambulatory pathway. They were reassessed every two days with a chest x-ray in the ambulatory care unit. The patients with Pneumostat ${ }^{\mathrm{TM}}$ valve (Atrium Medical Corporation) were taught to check for airleak every day. Patient outcomes and complications were recorded. Patients with tension, iatrogenic or traumatic pneumothorax were excluded from the study.

Primary outcome measure

Success rate at day 5 defined as sustained complete re-expansion of lung with no air leak.

\section{Secondary Outcome measures}

Number of days spent with the chest drain in situ.

Complications like drain falling out, drain blockage, Infection

Number of patients requiring surgical treatment due to persisting air leak.

Results A total of 110 patients were reviewed with spontaneous pneumothorax, of which 54 were managed on the ambulatory pathway. (Table 1) The pneumothorax resolved successfully in $77 \%$ of the primaries pneumothoraces and $67 \%$ of the secondaries, with an overall resolution of $72 \%$. In the PSP, five patients $(16.7 \%)$ went on to have surgery due to non-resolution. Of the 24 SSP, eight $(33.3 \%)$ patients went on to have surgery due to non-resolution. Complications other than pain were minimal. The mean duration of drainage was 3.8 days in PSP and 5.9 days in SSP. This compares well with the median drainage of 6-8 days for inpatient management of PSP (BTS guidelines). ${ }^{1}$

\begin{tabular}{lll} 
Abstract S96 Table 1 & Results & \\
\hline & PSP & SSP \\
\hline Total number of patients & 37 & 75 \\
No. Eligible for Ambulatory pathway & 37 & 41 \\
No. treated on ambulatory pathway & 30 & 24 \\
Average age (range) & 29.7 & 59.7 \\
Sex (M:F) & $25: 5$ & $16: 8$ \\
Size of pneumothorax (L:S) & All large & $23: 1$ \\
Resolution at day 5 & $23(76.7 \%)$ & $16(66.7 \%)$ \\
No. Requiring surgery due to non-resolution & $5(16.7 \%)$ & $8(33.3 \%)$ \\
Average Length of hospital stay (days) & $0.6(0-3)$ & $1.08(0-6)$ \\
Average duration of outpatient follow-up (range in days) & $3.2(1-11)$ & $4.79(1-14)$ \\
Number of reviews (range) & $1.57(0-5)$ & $1.75(1-4)$ \\
\hline
\end{tabular}

Conclusion The success rate was $72 \%$ for all spontaneous pneumothorax patients managed almost exclusively as outpatients, which compares well with the $78 \%$ suggested in the meta-analysis by Brimms and Maskell. ${ }^{2}$ This study confirms that the use of chest drain with one-way valves in the ambulatory management of primary and selected secondary spontaneous pneumothoraces is safe with very few complications. This procedure clearly decreases the number of hospitalisation days and is thus cost saving.

\section{REFERENCES}

1 Mcduff A. BTS pleural disease guidelines. Thorax 2010;65(Suppl II):ii1-ii76.

2 Brims FJ, Maskell NA. Ambulatory treatment in the management of pneumothorax: a systematic review of the literature. Thorax 2013;68(7):664-9. 


\section{Correction}

Fawzi A, Maddekar N, Khan S, et al. S95 Ambulatory management of pneumothorax: is there a need for a dedicated pleural team-led service? Thorax 2016;71:A55-A56 doi:10.1136/ thoraxjnl-2016-209333.101

There are 2 corrections to this abstract:

1. Two authors, Ganaie B and Iqbal M, were omitted from the original publication and has now been included, due to this the author list order has been updated. The corrected author list of this abstract should be as follows:

Fawzi A, Maddekar N, Ganaie B, Bikmalla S, Osman W, Maqsood U, Khan S, Iqbal M, Haris M.

2. Corrections have been made to the 'Methods' and 'Results' section of this abstract. The changes are in bold.

Methods

Hospital attendances of pneumothorax at a large teaching hospital between 2008-2015 were reviewed. Type of pneumothorax was characterised: primary spontaneous (PSP), secondary spontaneous (SSP), iatrogenic (IP) and traumatic/post-operative. The data for PSP was then correlated against the data retrieved from the systematic review of outpatient pneumothorax management. ${ }^{1}$

Results

Total number of pneumothorax episodes were 877; PSP 266, SSP 229, IP 41 and traumatic/ post-operative 341. Average length of stay (LOS) for all episodes of pneumothorax was 12.39 days. LOS for PSP was 6.9 days. Total number of hospital admissions for PSP 266/7=38 patients/year. Extrapolated from systematic review 1: Successful outpatient PSP management $38 \times 78 \%=29.64$ patients/year. Potential bed days saved for PSP $(29.64 \times 6.9)=204 /$ year.

Thorax 2017;72:262. doi:10.1136/thoraxjnl-2016-209333.101corr1

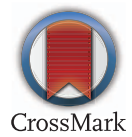

